\title{
Mechanical, Dielectric and Shielding Performance of Rice Husk/Polycaprolactone Composites Enhanced via Rice Husk Particles Inclusion
}

\author{
Abubakar Yakubu1, Zulkifly Abbas², Sirajo Abdullahi² \\ ${ }^{1}$ Department of Physics, Kebbi State University of Science and Technology, Aliero, Nigeria \\ ${ }^{2}$ Department of Physics, Universiti Putra, Serdang, Selangor, Malaysia \\ Email: abulect73@yahoo.com
}

How to cite this paper: Yakubu, A., Abbas, Z. and Abdullahi, S. (2020) Mechanical, Dielectric and Shielding Performance of Rice Husk/Polycaprolactone Composites Enhanced via Rice Husk Particles Inclusion. Open Access Library Journal, 7: e6514.

https://doi.org/10.4236/oalib.1106514

Received: June 10, 2020

Accepted: July 11, 2020

Published: July 14, 2020

Copyright $\odot 2020$ by author(s) and Open Access Library Inc.

This work is licensed under the Creative Commons Attribution International License (CC BY 4.0).

http://creativecommons.org/licenses/by/4.0/

\section{(c) (i) Open Access}

\begin{abstract}
Developing new absorbing and shielding materials with a large band of frequency and high performance to allow the coexistence of the electronic components without the damaging electromagnetic interference (EMI) is needed. For this reason, this work is focused on polycaprolactone (PCL) and rice husk particles (RHP) prepared at filler percentage of 0 to $60 \mathrm{wt} \%$ leading to the formation of PCL/RHP composites. The RHP was prepared by washing with water, acetone, sun-dried and grinded in a milling machine. The particles obtained were then sieved into sizes of 200, 400, 800 and $1000 \mu \mathrm{m}$. The PCL/RHP composites for each of the dimensions were prepared in a Thermo Haake blending machine. The paste obtained from the blend was then fabricated into pellets for different characterization purposes. Mechanical properties of the prepared composites were determined using different analysis tools, while the dielectric and shielding properties of the composites were investigated using the open ended coaxial probe via a vector network analyzer. The results from findings showed that tensile strength, impact strength, flexural strength, elongation at breakage and hardness and the dielectric constant of the samples were affected with inclusion of the RHP. However, the elongation at breakage was observed to decrease with increase in the weight (\%) of the RHP. The particle size of RHP played a significant role in enhancing dielectric constant and shielding effectiveness (SE) of the composites, as analysis showed that PCL/RHP composites' average dielectric constant was 3.6, 3.0, 2.7 and 2.4 while SE was $-12.4,-10.6,-7.9,-6.0 \mathrm{~dB}$ for the $200,400,800$ and $1000 \mu \mathrm{m}$, respectively. Based on the result obtained it is concluded that the manufactured composites can be tailored for shielding applications in the telecommunication industries.
\end{abstract}




\section{Subject Areas}

Applied Physics

\section{Keywords}

Polymer, Rice Husk, Polycaprolactone (PCL), Particle Size, Dielectric Constant

\section{Introduction}

Fillers greatly enhance the dimensional stability, electromagnetic properties, attenuation, shielding performance, impact resistance, tensile and compressive strength, abrasion resistance and thermal stability when incorporated into polymers. Fillers which merely increase the bulk volume, and hence, reduce price, are known as extender fillers while those that improve the mechanical and electrical properties particularly tensile strength and dielectric constant are termed as reinforcing fillers (Catto, Júnior, Hansen et al., 2019) [1].

Usage of working electronic devices in the frequency band of microwave region has grown rapidly over the few decades, whereas the electromagnetic interference (EMI) has immensely increased. Therefore, there are radiation perturbations of large degree produced in electronic systems of both military and civil telecommunication.

There has been an increase in the use of filled PCL in electrical and automotive engineering. This is attributed to the unique property which it exhibits and which enables it to substitute conventional materials in demanding engineering applications (Saunders and Ma, 2019) [2].

The use of fiber-based materials as reinforcing fillers for thermoplastics has received great attention from a number of researchers and manufactures in recent years (Ahmad, Abbas, Aziz et al., 2018 [3]; Delviawan, Suzuki, Kojima et al., 2019 [4]). The addition of the renewable natural filler in polymeric composites aims to produce unique characteristics of great versatility, light weight, biodegradability and recyclability with good specific properties (Yakubu, Zulkifli, Esa et al., 2015) [5].

In comparison with other fillers such as traditional glass fiber and inorganic mineral fillers, agricultural waste fiber is inexpensive, with low density and non-abrasive to processing machinery (Girişken, Yanmaz, Can, et al., 2020) [6].

Cui, Honda, Asoh, et al. (2020), studied polypropylene (PP), which is one of the typical commodity thermoplastics, that has been mostly used as a polymeric matrix in the wood composites researches using conventional methods in its preparation [7]. They investigated on mechanical properties of the composites.

Sundarababu, Anandan, \& Griskevicius, (2020), reported on the production of rice husk polymer composites with cocoanut shells using the hand layup method [8]. They investigated mechanical properties such as tensile strength and flexural 
strength. Based on the result obtained, they concluded that the manufactured composites can be used for engineering applications.

Kim, Lee, Choi, et al. (2007), observed that MAPP-treated polypropylene composites showed improved mechanical and thermal stability. This enhancement is also observed in the system of polyethylene and wood powder [9]. Guo, Song, Wang, et al. (2006), revealed that the storage modulus of wood flour filled polypropylene composites was improved when MAPP was applied [10].

From the literature reviewed, most of the researchers were only dealing with polymeric materials that melt at high temperature (polypropylene). This high temperature melting polymers are not flexible hence causes difficulty when fabricating materials into desired shapes. For this reason, our research is focused on changing the polymer to a low melting point type which is more flexible for fabrication and easy for blending with waste fibers.

In this research, the mechanical, dielectric and shielding properties of the PCL/RHP composites at various filler contents ( 0 - $60 \mathrm{wt} \%)$ and different particle sizes are investigated. The significance of this work lies on the pretext of understanding behaviors of the RHP weight (\%) and filler sizes with the intent to accurately produce composite for specific applications which were absent in earlier researches.

\section{Experimental Work}

\subsection{Materials}

Commercial grade polycaprolactone (PCL) was supplied by Sigma Aldrich. The melt flow index, density and melting temperature are $12.5 \mathrm{~g} / 10 \mathrm{~min}, 1.145 \mathrm{~g} / \mathrm{cm}^{3}$, and $70^{\circ} \mathrm{C}$, respectively. RHP is prepared by washing the raw rice husk (RH) with water and dipping the washed husks into acetone for a period of 5 - 10 minutes before Sun drying. The husk is sundried for 48 hours before moving it to the milling machine. The dried husk is then milled into powdery form with a local grinding machine. The milled powder is then sieved to sizes of 200, 400, 800 and $1000 \mu \mathrm{m}$. Rice husk is selected as filler in this work due to its light weight, non-corrosive and it's less abrasion to processing equipment. In addition, it has high specific strength modulus, low cost, and it is abundant availability in most geographic regions in Nigeria and the world at large.

\subsection{Composites Preparation}

The prepared RHP and the supplied PCL were blended in a Thermo Haake extruder Polydrive three-phase motor with a drive of $1.5 \mathrm{~kW}, 3 \times 230 \mathrm{~V}, 40 \mathrm{~A}$ and speed range of $0-120 \mathrm{rpm}$. The ratio of material used in the preparation of the composites is shown in Table 1.

In this method, the machine is set to $90^{\circ} \mathrm{C}$ for heating the vial, the rotation of the rotors was set to $50 \mathrm{rpm}$. After the machine has reached the required temperature $\left(90^{\circ} \mathrm{C}\right)$, the polycaprolactone $(\mathrm{PCL})$ is poured into the vial of the Thermo Haake heating block. After 5 minutes, RHP for a required proportion is 
Table 1. Sample preparation weight ratio.

\begin{tabular}{cccc}
\hline Weight (\%) & Rice Husk Powder (g) & Polycaprolactone (g) & Total \\
\hline 10 & 4 & 36 & 40 \\
20 & 8 & 32 & 40 \\
30 & 12 & 28 & 40 \\
40 & 16 & 24 & 40 \\
50 & 20 & 20 & 40 \\
60 & 24 & 16 & 40 \\
\hline
\end{tabular}

poured into the vial. The mixture is left for another 20 minutes before taken out and fabricated into desired dimension using hot and cold press.

\section{Characterization of PCL/RHP Composites}

\subsection{Mechanical Properties}

Tensile strength properties are carried out on an Instron $5585 \mathrm{H}$ using the Instron Bluehill 2, version 3.4 software. Tests were performed in accordance with ASTM standard D638 using a crosshead speed of $5 \mathrm{~mm} / \mathrm{min}$. The specimens were V-notched at 458 angle using a Tinius Olsen specimen notcher (model 899). The hardness of the composites was determined using ASTM D 785. All measurements were carried out at room temperature.

\subsection{Shielding Effectiveness and Dielectric Properties}

Measurement of scattering parameter and dielectric constant were carried out using rectangular waveguide which is connected to a network vector analyzer (VNA) via a high precision coaxial cable. The VNA model is Agilent PNA-L N5230A, Agilent Technologies, USA. Full two port calibration of Thru-Reflect-Line (TRL) is carried out on the instrument to validate measurement. This method reduces the number of errors emanating from the components i.e. cables and connectors. From the calibration done, reflection loss was limited to be less than $0.2 \mathrm{~dB}$ in the measurement set-up (Figure 1).

Material shielding of EMI is defined as the attenuation by absorption and reflection of the power incident, or the incident power $\left(P_{i}\right)$ to transmitted power $\left(P_{t}\right)$ of an electromagnetic wave (Ahmad, Abbas, Sidek et al., 2018) [3]. The expression for shielding effectiveness is:

$$
\mathrm{SE}(\mathrm{dB})=10 \log (10) P_{i} / P_{t}
$$

\section{Results and Discussion}

\subsection{Mechanical Properties}

The results for the mechanical properties of PCL/RHP composites are shown in Figures 2-6. Figure 2 shows the effect of filler (\%) and particle sizes on the tensile strengths for PCL and PCL/RHP composites. The tensile strength of composites 


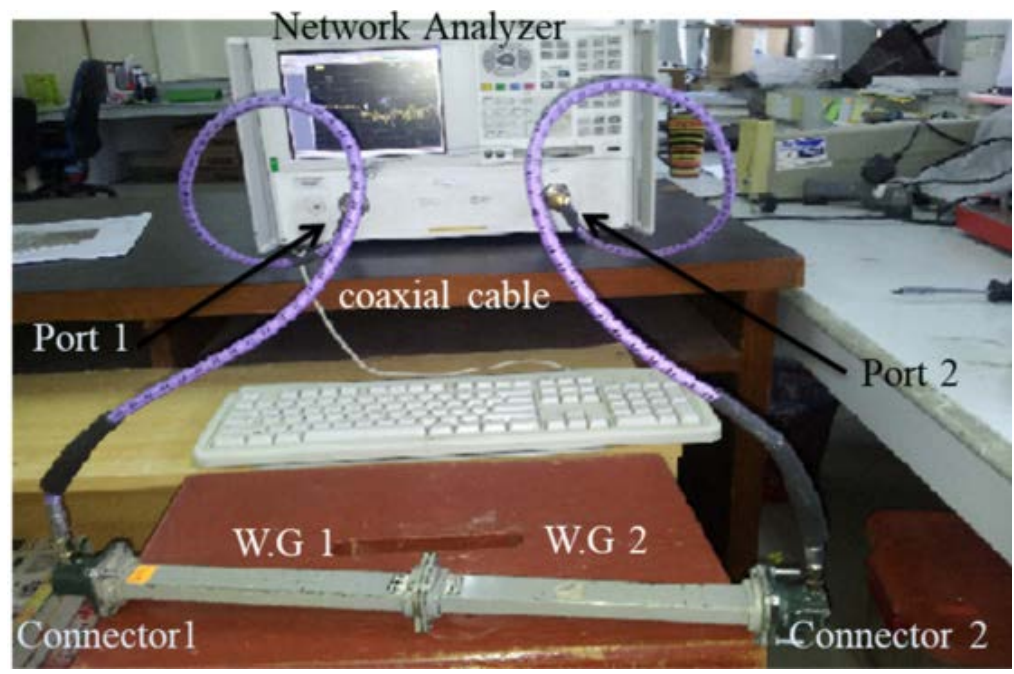

Figure 1. Measurement setup for scattering parameter and dielectric constant.

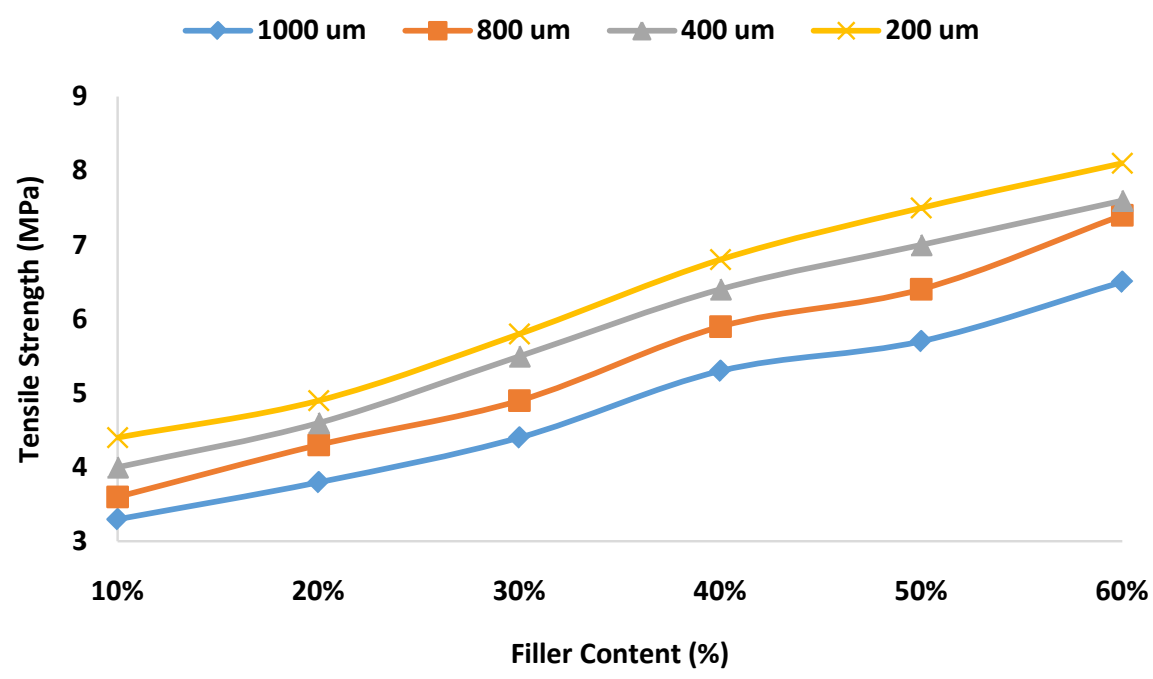

Figure 2. Tensile strength and filler (\%) of PCL/RHP composites.

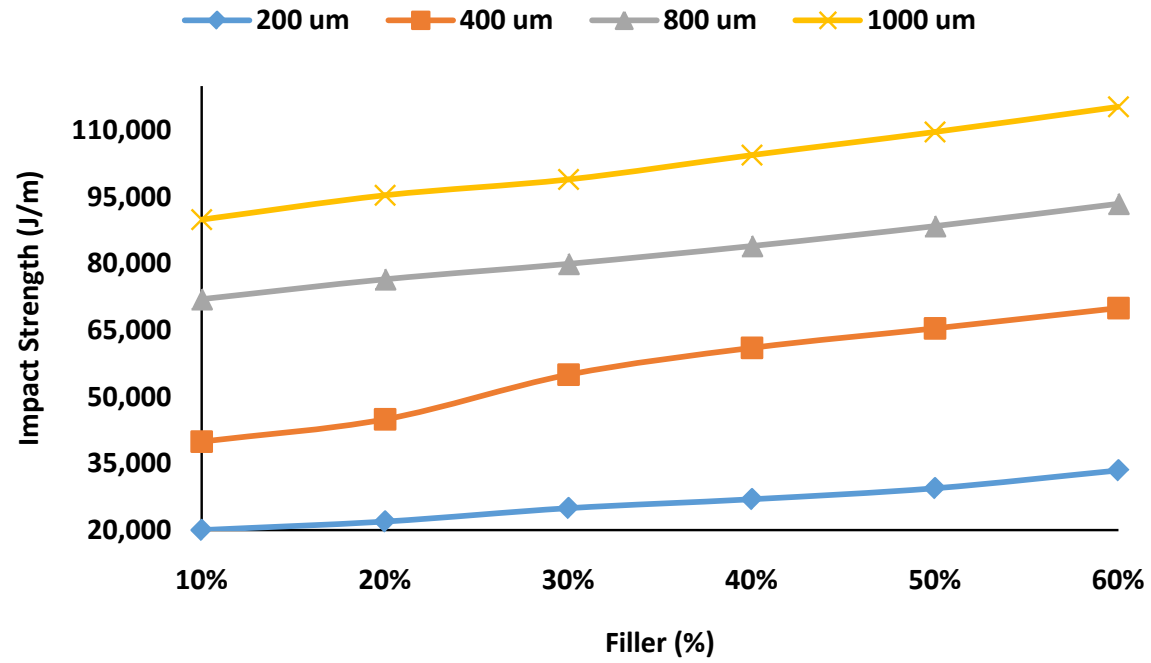

Figure 3. Impact strength and filler content (\%) of PCL/RHP composites. 


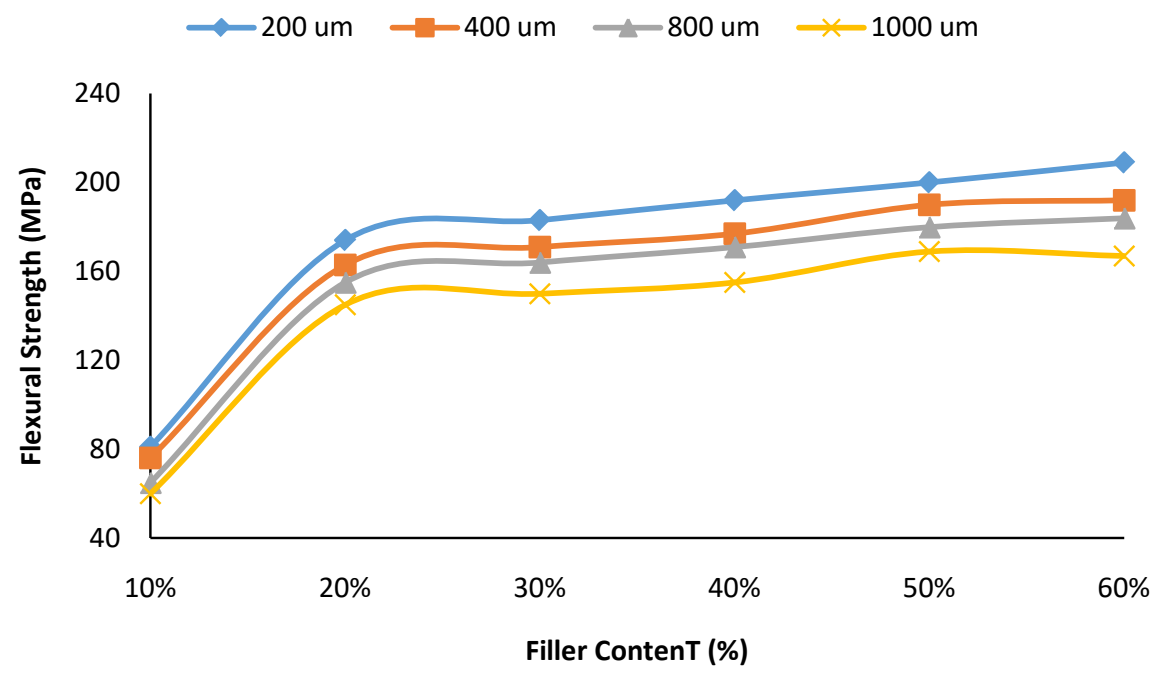

Figure 4. Flexural strength and filler content (\%) of PCL/RHP composites.

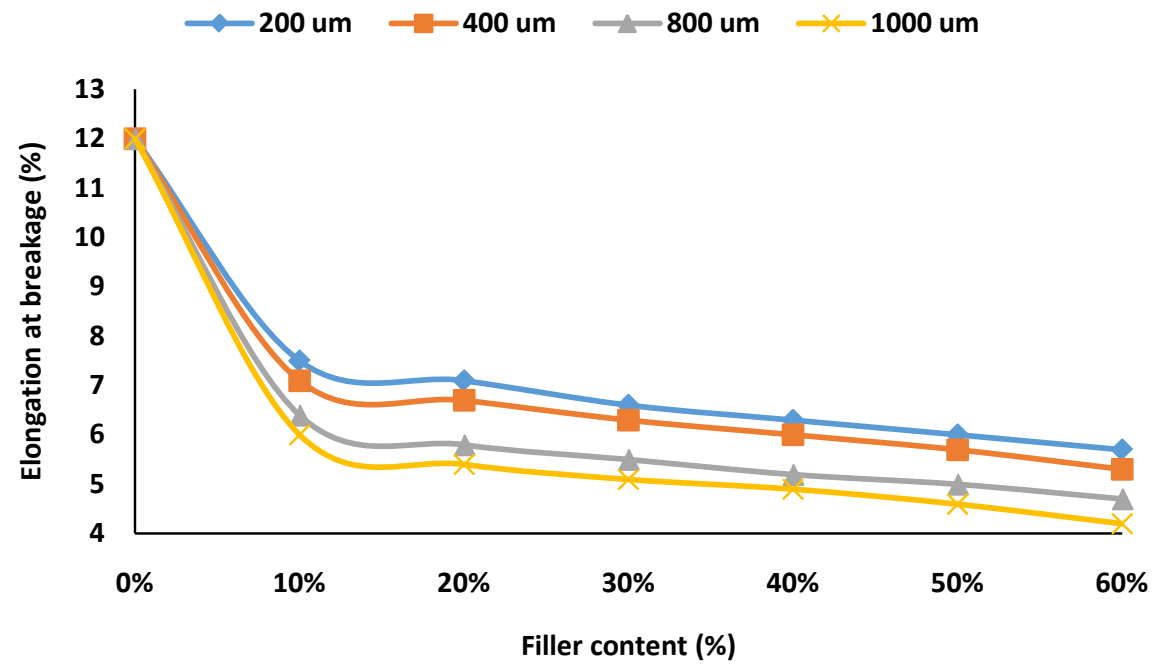

Figure 5. Elongation at breakage and filler content (\%) of PCL/RHP composites.

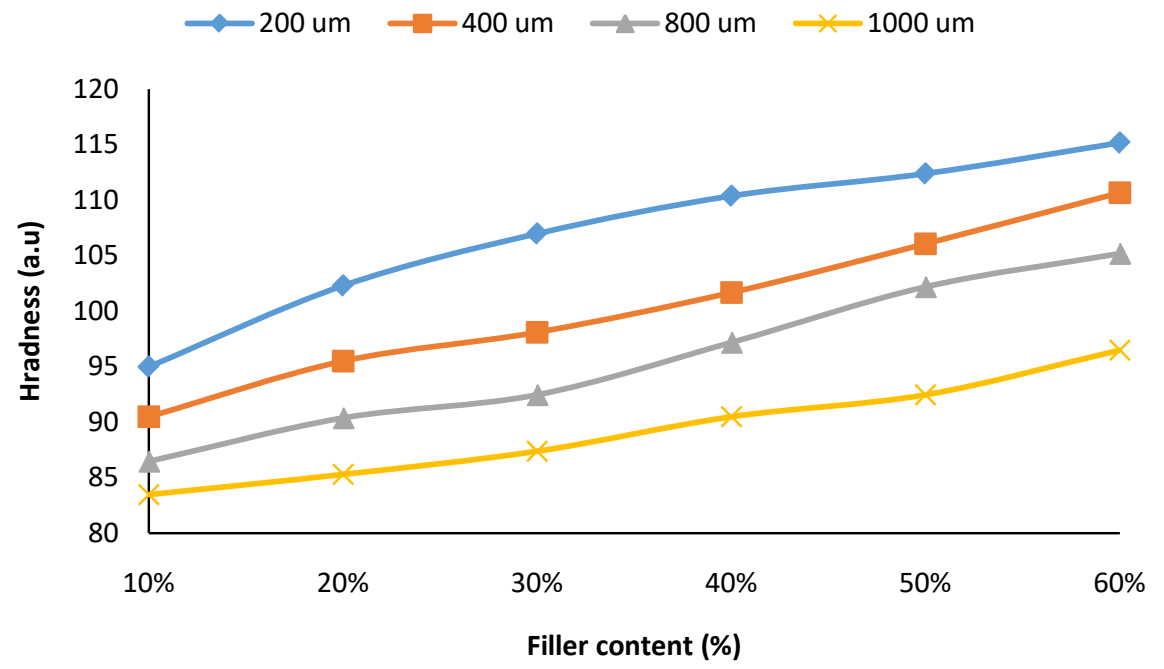

Figure 6. Hardness and filler content (\%) of PCL/RHP composites. 
is observed to increase with increase in RHP filler (\%) and particle size. It is clear that the smaller the particle size of filler, the higher the tensile strength of the composite at any filler (\%). The better dispersion and filler-matrix interaction between the two compounds may be the main reasons or factors responsible for the observed trend. Similar observations have been reported in (Abdalhadi, Abbas, Ahmad et al., 2017) [11]. In all four samples, it is affirmed that smaller sample size had better tensile strength at higher filler compositions.

The impact strength of composites is observed to increase with increase in RHP filler (\%) as shown in Figure 3. There is significant enhancement of the composites indicating that RHP filler is more effective in distributing the applied stress over a large volume at the base of the notch, and which helped to prevent propagation of cracks by carrying large part of the load in the area under the crack (Musinki and McDowell, 2016) [12]. The increase in impact strength of the polymer composite with increase in filler content has been reported (Ahmad Saffian, Hyun-Joong, Tahir et al., 2019) [13]. However, the impact strength of the prepared composites is observed to decrease with reduced sample sizes. Hence it is concluded that increasing the particle size of filler would significantly decrease the level of stress concentration in the composites with a resultant increase in impact strength.

Figure 4 shows that the flexural strength of PCL/RHP composites increases with increase in filler (\%). It is suggested that both particle size and filler (\%) enhances the abrasion and impact strength of the composites. However, there is a tendency that the flexural strength might remain constant and even decreases as filler \% exceeds our investigated content weight.

Fillers can be considered as structural elements embedded in polymer matrixes. The percentage of filler used in our research might not be strong enough to confine the molecules of polycaprolactone. Accordingly, exceedingly confined strains might have occurred at the concentrations investigated, leading to de-wetting between PCL and the filler, thus, leaving essentially a matrix that is not ductile (Peng, Nair, Chen et al., 2018) [14]. Such reduction in elongation at breakage of composite is observed as filler content increases irrespective of filler particle size (Figure 5).

Shown in Figure 6 is the graph of sample hardness and filler (\%) of composite for different particle sizes. Observation shows that the hardness of PCL/RHP composites increases with increase in filler incorporated into PCL. In addition, the result showed that smaller particle size has higher hardness, which might be attributed to large surface area due to close boundary spacing in the domain walls. The decrease in hardness as particle size increases is attributed to increase in resistance strength of polymer to plastic deformation (Sanjay, Madhu, Jawaid et al., 2018) [15].

\subsection{Dielectric Properties}

The increase in dielectric constant is due to the enhancement of interfacial polarization due to the effect of interfacial lattice disorder of the PCL and RHP 
thereby increasing the dielectric constant as particles sizes decreases (Mensah, Abbas, Azis et al., 2019) [16]. Further reason for the increases in dielectric constant is associated with compactness of smaller sizes, less air gaps and, good contact between the constituent particles leading to increase surface density. The resulting increased surface density and interfacial polarization, led to the overall increase in dielectric constant. The decrease in dielectric constant as frequency increases from $5 \mathrm{GHz}$ to $20 \mathrm{GHz}$ is consistent with materials with interfacial polarization (Yakubu, Abbas, Esa et al., 2015) [5].

The loss factor shown in Figure 7 represents the loss in energy of the propagated waves through the composites. The results confirmed that that the 1000 um particle sized composites had the lowest loss which is in good agreement with the result obtained for the dielectric constant (see Figure 8). In addition,

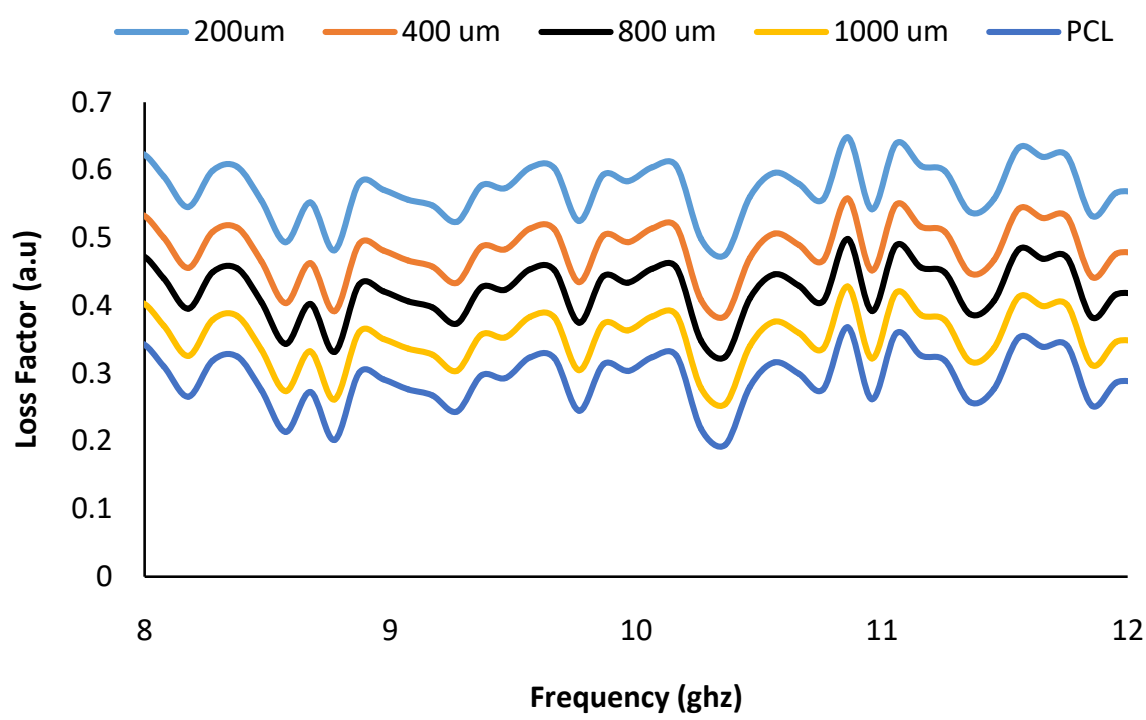

Figure 7. Loss factor and filler (\%) of PCL/RHP composites.

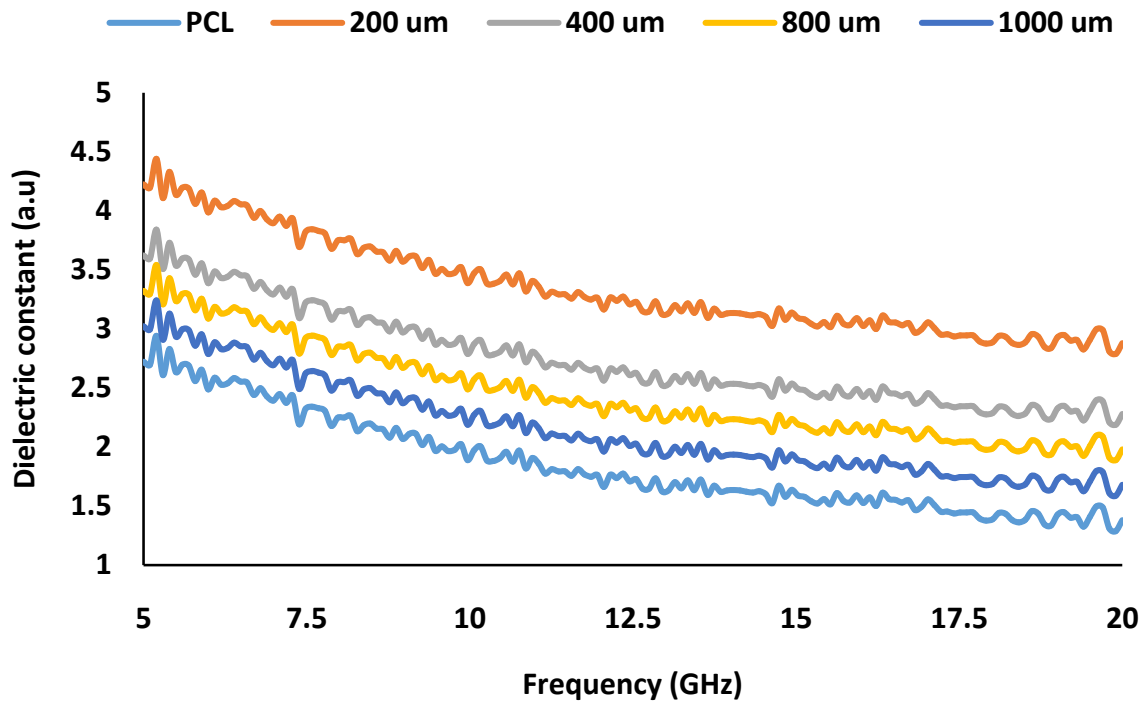

Figure 8. Dielectric constant and filler (\%) of PCL/RHP composites. 
the dielectric measurement result confirms the incorporation of the smaller particle into the polymer matrix where the lowest particle composite produced the highest dielectric constant for the composites investigated.

\subsection{Shielding Effectiveness}

Variation in the SE shielding for the PCL/RHP composites at different filler percentages is illustrated in Figure 9. Observation shows that increasing the RHP particle size boosted the SE of the composites. The rate of increase was higher in the smaller sized particles which is attributed to the interaction of electromagnetic fields with electric diploes thus increasing the interfacial polarization of the PCL (Ahmad, Zulkifli, Sidek et al., 2018) [3]. Shielding effectiveness was $-5 \mathrm{~dB}$ for PCL and increased to $-12.5 \mathrm{~dB}$ for the $200 \mathrm{um} \mathrm{PCL/RHP} \mathrm{composites} \mathrm{at} 8$ GHz.

As signals from a source propagate and interact with surface of a specimen, different signals are generated due to the interaction. From the secondary electron emitted from the specimen, functions like chemical bonding, surface fracture and particles dispersion in specimen can be obtained. For the samples used in this research, surface information was obtained by recorded signals from the samples. Scanning electron micrographs (SEM) depicted in Figure 10, depicts the surface morphologies on the magnification $(300 \times)$ for the 200, 400, 800 and $100 \mu \mathrm{m}$ RHP. Observation on the $300 \times$ magnified micrographs shows that the surface of the $200 \mu \mathrm{m}$ particles sizes are almost uniform and well bonded due to increase surface density. The diameter of the particles is smaller than that of the $400 \mu \mathrm{m}$. The $400 \mu \mathrm{m}$ particles show coarse larger particles due to increase in grain boundaries. The particles are closely parked but showed less bonding due to large spacing between particles. The $800 \mu \mathrm{m}$ particles show that the particles are spherical in form with larger spacing attributed to large boundary walls. The morphology $1000 \mu \mathrm{m}$ particles are indeed larger than other particles due to their spacing and grain growth domain, the interaction of these particles will certainly

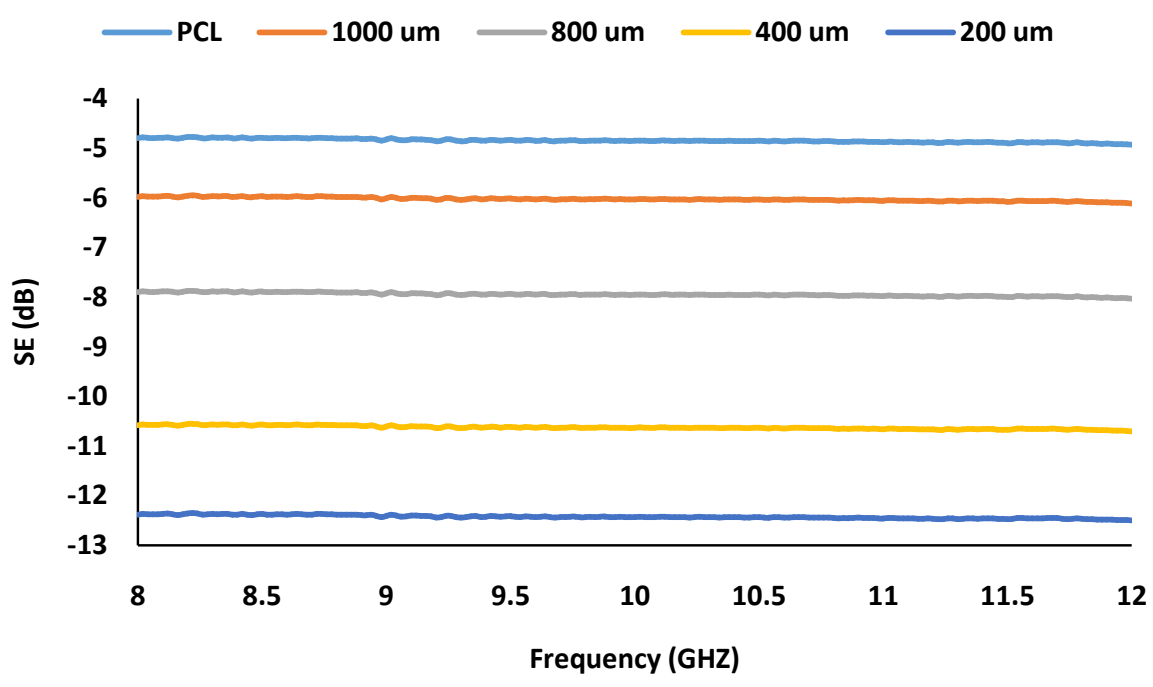

Figure 9. EMI shielding effectiveness for PCL/RHP composites. 


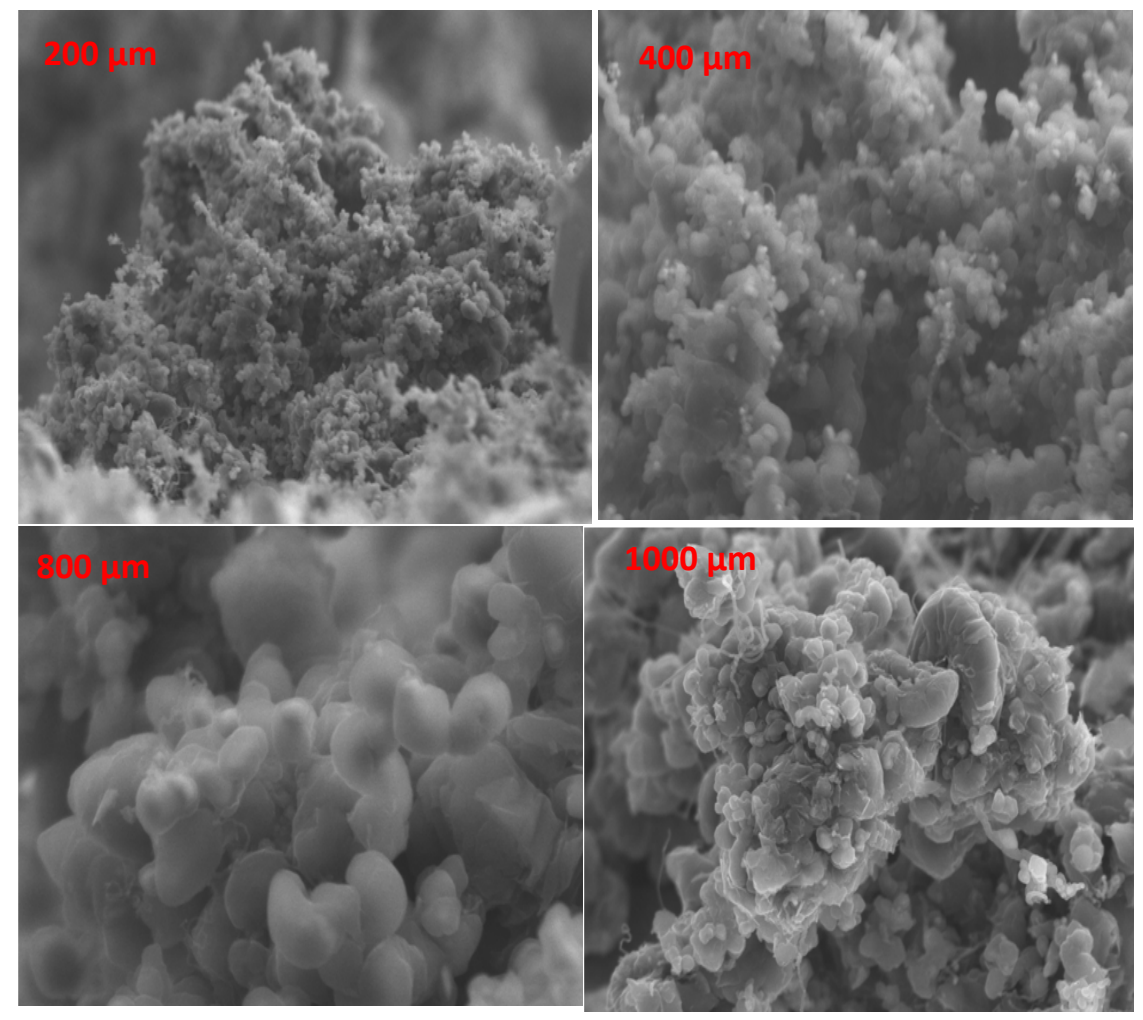

Figure 10. SEM micrograph for the RHP.

create porous surface indicating that it will interact poorly with the polymer matrix.

\section{Conclusions}

Melt blending technique was used to prepare PCL/RHP composites reinforced with different filler loadings of RHP particles. The RHP filler (\%) was found to improve the hardness of composites. The impact strength, and tensile strength were significantly affected by the addition of RHP filler. However, the impact strength decreased with increase in particle size whilst the tensile strength increased with increasing particle size.

The SE results confirmed that the efficiency of shielding increases with the percentages increment of the filler and this was due to the decrease in grain boundaries walls on the surface of the composites. There was increase in the dielectric properties of the composites as particles' sizes decrease attributed to increase surface area within the composite which in-turn enhanced the shielding performance of the composites. The prepared composites are good for small shield application in military and telecommunication devices.

\section{Acknowledgements}

The authors wish to thank the Department of Physics, Kebbi State University of Science and Technology, Aliero, Nigeria and the Department of Physics, Universiti Putra Malaysia for providing facilities for the research. 


\section{Conflicts of Interest}

The authors declare no conflicts of interest regarding the publication of this paper.

\section{References}

[1] Catto, A.L., Júnior, M.A.D., Hansen, B., Francisquetti, E.L. and Borsoi, C. (2019) Characterization of Polypropylene Composites Using Yerba Mate Fibers as Reinforcing Filler. Composites Part B: Engineering, 174, Article ID: 106935. https://doi.org/10.1016/j.compositesb.2019.106935

[2] Saunders, L. and Ma, P.X. (2019) Self-Healing Supramolecular Hydrogels for Tissue Engineering Applications. Macromolecular Bioscience, 19, Article ID: 1800313. https://doi.org/10.1002/mabi.201800313

[3] Ahmad, A.F., Abbas, Z., Ab Aziz, S., Obaiys, S.J. and Zainuddin, M.F. (2018) Synthesis and Characterisation of Nickel Oxide Reinforced with Polycaprolactone Composite for Dielectric Applications by Controlling Nickel Oxide as a Filler. Results in Physics, 11, 427-435. https://doi.org/10.1016/j.rinp.2018.08.041

[4] Delviawan, A., Suzuki, S., Kojima, Y. and Kobori, H. (2019) The Influence of Filler Characteristics on the Physical and Mechanical Properties of Wood Plastic Composite (s). Reviews in Agricultural Science, 7, 1-9. https://doi.org/10.7831/ras.7.1

[5] Yakubu, A., Abbas, Z., Esa, F. and Tohidi, P. (2015) The Effect of ZnO Nanoparticle Filler on the Attenuation of $\mathrm{ZnO} / \mathrm{PCL}$ Nanocomposites Using Microstrip Line at Microwave Frequency. International Polymer Processing, 30, 227-232.

https://doi.org/10.3139/217.2993

[6] Girişken, Ç., Yanmaz, C., Can, B.N., Ülçer, Y. and Menceloğlu, Y.Z. (2020) Low Density, High Modulus Polypropylene Wood Composites Prepared by Using Thermo Kinetic Mixer. AIP Conference Proceedings, 2205, Article ID: 020020. https://doi.org/10.1063/1.5142935

[7] Cui, X., Honda, T., Asoh, T.A. and Uyama, H. (2020) Cellulose Modified by Citric Acid Reinforced Polypropylene Resin as Fillers. Carbohydrate Polymers, 230, Article ID: 115662. https://doi.org/10.1016/j.carbpol.2019.115662

[8] Sundarababu, J., Anandan, S.S. and Griskevicius, P. (2020) Evaluation of Mechanical Properties of Biodegradable Coconut Shell/Rice Husk Powder Polymer Composites for Light Weight Applications. Materials Today. Proceedings, 5, 14458-14467. https://doi.org/10.1016/j.matpr.2020.04.095

[9] Kim, H.S., Lee, B.H., Choi, S.W., Kim, S. and Kim, H.J. (2007) The Effect of Types of Maleic Anhydride-Grafted Polypropylene (MAPP) on the Interfacial Adhesion Properties of Bio-Flour-Filled Polypropylene Composites. Composites Part A: Applied Science and Manufacturing, 38, 1473-1482.

https://doi.org/10.1016/j.compositesa.2007.01.004

[10] Guo, C.G., Song, Y.M., Wang, Q.W. and Shen, C.S. (2006) Dynamic-Mechanical Analysis and SEM Morphology of Wood Flour/Polypropylene Composites. Journal of Forestry Research, 17, 315-318. https://doi.org/10.1007/s11676-006-0072-7

[11] Abdalhadi, D.M., Abbas, Z., Ahmad, A.F. and Ibrahim, N.A. (2017) Determining the Complex Permittivity of Oil Palm Empty Fruit Bunch Fibre Material by Open-Ended Coaxial Probe Technique for Microwave Applications. BioResources, 12, 3976-3991. https://doi.org/10.15376/biores.12.2.3976-3991

[12] Musinski, W.D. and McDowell, D.L. (2016) Simulating the Effect of Grain Boundaries on Microstructurally Small Fatigue Crack Growth from a Focused Ion Beam 
Notch through a Three-Dimensional Array of Grains. Acta Materialia, 112, 20-39. https://doi.org/10.1016/j.actamat.2016.04.006

[13] Ahmad Saffian, H., Hyun-Joong, K., Md Tahir, P., Ibrahim, N.A., Lee, S.H. and Lee, C.H. (2019) Effect of Lignin Modification on Properties of Kenaf Core Fiber Reinforced Poly(Butylene Succinate) Biocomposites. Materials, 12, 4043.

https://doi.org/10.3390/ma12244043

[14] Peng, Y., Nair, S.S., Chen, H., Yan, N. and Cao, J. (2018) Effects of Lignin Content on Mechanical and Thermal Properties of Polypropylene Composites Reinforced with Micro Particles of Spray Dried Cellulose Nanofibrils. ACS Sustainable Chemistry \& Engineering, 6, 11078-11086.

https://doi.org/10.1021/acssuschemeng.8b02544

[15] Sanjay, M.R., Madhu, P., Jawaid, M., Senthamaraikannan, P., Senthil, S. and Pradeep, S. (2018) Characterization and Properties of Natural Fiber Polymer Composites: A Comprehensive Review. Journal of Cleaner Production, 172, 566-581. https://doi.org/10.1016/j.jclepro.2017.10.101

[16] Mensah, E.E., Abbas, Z., Azis, R.A.S. and Khamis, A.M. (2019) Enhancement of Complex Permittivity and Attenuation Properties of Recycled Hematite $\left(\alpha-\mathrm{Fe}_{2} \mathrm{O}_{3}\right)$ Using Nanoparticles Prepared via Ball Milling Technique. Materials, 12, 1696. https://doi.org/10.3390/ma12101696 